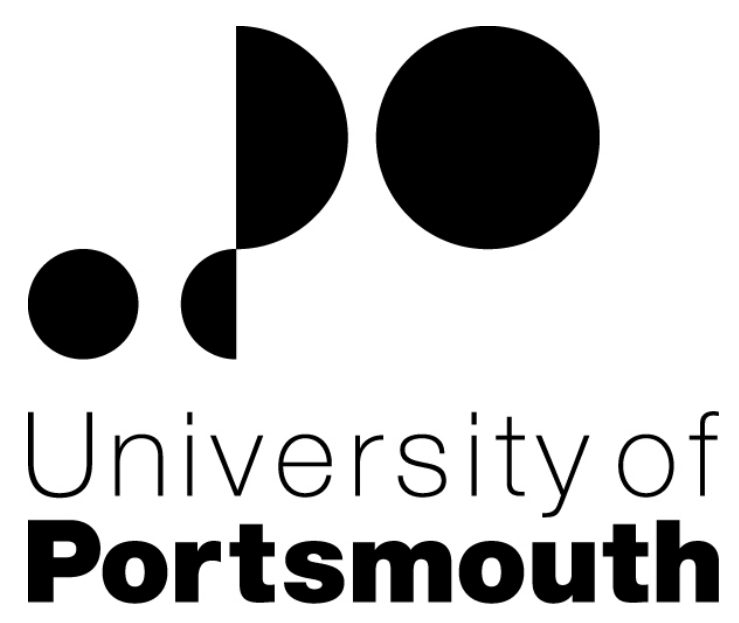

CEMARE Research

Paper 166

Market power and

compliance with

output quotas

A Hatcher 
University of Portsmouth

St. George's Building

141 High Street

Portsmouth

PO1 2HY

United Kingdom

First published University of Portsmouth 2010

Copyright $\odot$ University of Portsmouth 2010

All rights reserved. No part of this paper may be reproduced, stored in a retrievable system or transmitted in any form by any means without written permission from the copyright holder.

For bibliographic purposes this publication may be cited as: Hatcher, A. 2010. Market power and compliance with output quotas. CEMARE Res. pap. no.166

Contact Author:

Aaron Hatcher

CEMARE

(Centre for the Economics

and Management of Aquatic Resources)

University of Portsmouth

St. George's Building

141 High Street

Portsmouth

PO1 2HY

E-mail: aaron.hatcher@port.ac.uk

ISSN 0966-792X

Abstracted and Indexed in:

Aquatic Sciences and Fisheries Abstracts 


\title{
Market power and compliance with output quotas
}

\author{
Aaron Hatcher* \\ Centre for the Economics and Management of Aquatic Resources, \\ University of Portsmouth, United Kingdom
}

*Address for correspondence:

CEMARE, University of Portsmouth,

St. George's Building, 141 High Street,

Portsmouth PO1 2HY, United Kingdom

Tel. $+44(0) 2392848510$

E-mail: aaron.hatcher@port.ac.uk 


\title{
Market power and compliance with output quotas
}

\author{
Aaron Hatcher* \\ Centre for the Economics and Management of Aquatic Resources, \\ University of Portsmouth, United Kingdom
}

*Address for correspondence:

CEMARE, University of Portsmouth, St. George's Building, 141 High Street, Portsmouth PO1 2HY, United Kingdom

Tel. +44 (0)239284 8510

E-mail: aaron.hatcher@port.ac.uk

\begin{abstract}
This paper examines the compliance behaviour of a dominant firm in an output quota market when the firm is able to exercise market power in both the quota and the output markets. Even in the absence of enforcement, under certain conditions the firm may comply or even over-comply with its quota. The only unambiguous requirement is that the firm's initial quota endowment is strictly positive. Otherwise, the firm will always cheat. These results appear robust to compliance or non-compliance in the competitive fringe.
\end{abstract}

Keywords: ITQs; tradeable quotas; market power; non-compliance. 


\section{Introduction}

The basic efficiency properties of a system of tradeable output quotas, such as ITQs (individual transferable quotas) in fisheries, are well documented. These largely mirror the basic properties of marketable emissions (pollution) permits, on which a considerable literature now exists. One essential difference between output quotas and pollution permits, of course, is that the former define rights directly over production of a marketable good or goods, which raises the possibility of firms being able to exercise market power directly and simultaneously in both quota and output markets. This is an area, however, which has received relatively little attention. In particular, there is the interesting possibility that the ability to exercise market power in the output market may have an impact upon a firm's compliance behaviour in the quota market.

In the pollution permit literature, Misiolek and Elder [14] examine the simultaneous exercise of market power in permit and output markets, but in their model permits and output are not directly related, although the same firms participate in both markets and pollution permits are, de facto, necessary in order to produce for a local market. In this setting, Misiolek and Elder identify the possibility for what they term "exclusionary manipulation" of pollution permits, whereby firms use permit market power in order to raise rivals' costs or to deter new entrants. The welfare implications of the concurrent exercise of market power in pollution permit and output markets have been examined by Malueg [13], Innes, Kling and Rubin [10] and Sartzetakis [15, 16]. Like Misiolek and Elder, all these authors assume the equivalence of permit demands and emission levels, i.e., that there is perfect compliance and that firms do not hold more permits than is 
required by the regulator. Compliance by a dominant firm in a pollution permit market is considered by Malik [12], extending the earlier work of Hahn [7] and van Egteren and Weber [5] on permit market power. As well as exploring the effects of cheating, Malik identifies the conditions under which a dominant firm will hold excess permits.

Despite the often expressed concerns of policy makers and industry, few studies have examined the implications of either market power or non-compliance for ITQ markets, however. Anderson [1] models the profit-maximising behaviour of a (compliant) fishing firm which has market power in both the quota market and the corresponding output market. He finds that if the dominant firm is initially allocated all the quota, in exercising monopoly power it will find it profitable to hold quota in excess of its level of production, so increasing the output price. In the case where the dominant firm initially owns none of the quota, he finds no incentive for the firm to acquire excess quota, a result which he generalises to any firm with monopsony power in the quota market. In a recent paper, Anderson [2] revises this conclusion, but does not go on to examine further the conditions for the exercise of market power in both quota and output markets. Armstrong [3] looks at market power and efficiency in a dynamic quota allocation model, along the lines of the pollution permit model in Hagem and Westskog [6], but focuses only on market power in the quota market. To date, only two studies have analysed the impact of non-compliance upon ITQ markets. Chavez and Salgado [4] follow the pollution permit literature in assuming that firms' expected penalties for non-compliance depend upon their quota violations measured in level terms (e.g., Malik [11,12]), deriving similar results (for example, non-compliance is found to always reduce quota demands). Hatcher [8] adopts a 
more general specification of the violation argument in the expected penalty function and shows that the impact of non-compliance on firms' quota demands is less straightforward, with the "level violation" model arguably being a special case.

The present paper examines both compliance and market power in an output quota market. The basic model follows closely the pollution permit model of Malik [12], although the notation follows Hatcher [8]. After establishing some preliminary results for a competitive firm, we examine firstly the compliance behaviour of a firm with market dominance in the quota market only and then consider a firm with market power in both quota and output markets. Here, provided the dominant firm's initial quota allocation is greater than zero, the firm may choose to hold excess quota in relation to its output level, or it may cheat, depending upon the relative capacities of the dominant firm and the competitive fringe and the slopes of the (inverse) demand curves for quota and output. If the initial quota allocation to the dominant firm is zero, on the other hand, it will unambiguously cheat, although its quota demand may still be positive even in the absence of enforcement. After a brief consideration of the impact of non-compliance in the competitive fringe, a final section contains some concluding remarks.

An appendix presents a rigorous examination of the impact of non-compliance on a competitive firm's quota demand when expected penalties are modelled as a function of relative, rather than level, violations. This expands on the analysis in Hatcher [8] and corrects an error in that earlier paper. 


\section{Preliminaries}

We consider an industry in which there are a large number of independently operated, profit-maximising firms producing a single good. There is one dominant firm, indexed $i=1$, and a fringe of competitive firms which we represent, without loss of generality, by a single price taking firm, indexed $i=2$. For the fringe firm, we have the short run (social) benefit function

$$
B_{2}\left(q_{2}\right) \equiv p q_{2}-c_{2}\left(q_{2}\right),
$$

where $q_{2}$ is output, $p$ is the output price and $c_{2}\left(q_{2}\right)$ are variable costs. We assume $c_{2}^{\prime \prime}\left(q_{2}\right)>$ 0 , so that $B_{2}\left(q_{2}\right)$ is strictly concave in output. The necessary condition for (unconstrained) benefit maximisation by the fringe firm is then, as usual, $B_{2}^{\prime}\left(q_{2}^{*}\right) \equiv p-c_{2}^{\prime}\left(q_{2}^{*}\right)=0$.

In a given period, a social planner or resource manager sets a total output quota $\Omega$ for the industry. Quota is freely (costlessly) traded between firms and each firm demands an amount of quota $Q_{i}^{*} \geq 0$ at market equilibrium, where we assume the market clearing condition $Q_{1}^{*}+Q_{2}^{*}=\Omega$ holds. A compliant competitive firm, i.e., a firm which always chooses $Q_{2}^{*} \geq q_{2}^{*}$ irrespective of any pecuniary incentive to do otherwise, then faces the short run profit maximisation problem

$$
\max _{q_{2}, Q_{2}} B_{2}\left(q_{2}\right)-r Q_{2} \quad \text { s.t. } \quad q_{2} \geq 0, Q_{2} \geq 0, Q_{2} \geq q_{2},
$$

where $r$ is the short run (rental) price of quota. ${ }^{1}$ The corresponding Lagrangian

$$
\mathcal{L}=B_{2}\left(q_{2}\right)-r Q_{2}-\lambda_{2}\left(q_{2}-Q_{2}\right)
$$

\footnotetext{
1 Note that the firm's initial allocation of quota is assumed to be zero where the quota price is parametric to the firm. In this case a non-zero initial quota allocation makes no difference to the profit-maximising behaviour of the firm.
} 
gives the following Kuhn-Tucker conditions for an optimum

$$
\begin{gathered}
\mathcal{L}_{q}=B_{2}^{\prime}\left(q_{2}^{*}\right)-\lambda_{2} \leq 0, \quad q_{2}^{*} \geq 0, \quad \mathcal{L}_{q} q_{2}^{*}=0 \\
\mathcal{L}_{Q}=-r+\lambda_{2} \leq 0, \quad Q_{2}^{*} \geq 0, \quad \mathcal{L}_{Q} Q_{2}^{*}=0 \\
\mathcal{L}_{\lambda}=-q_{2}^{*}+Q_{2}^{*} \geq 0, \quad \lambda_{2}^{*} \geq 0, \quad \mathcal{L}_{\lambda} \lambda_{2}^{*}=0 .
\end{gathered}
$$

For $q_{2}^{*}=Q_{2}^{*}>0$, we have the necessary first-order conditions $B_{2}^{\prime}\left(q_{2}^{*}\right)=\lambda_{2}$ and $r=\lambda_{2}$ and hence the usual decision rule for a compliant price taking firm in a quota market,

$$
B_{2}^{\prime}\left(q_{2}^{*}\right)=r>0
$$

Here, the quota demand $Q_{2}^{*}(r)$ of the firm at a quota price $r$ is given by the inverse of the marginal benefit function $B_{2}^{\prime}\left(q_{2}\right)$ evaluated at $r$, i.e.,

$$
Q_{2}^{*}(r)=q_{2}^{*}(r) \equiv B_{2}^{\prime-1}(r)
$$

with the slope of the quota demand curve given by the slope of $B_{2}^{\prime-1}(r)$ :

$$
\frac{d Q_{2}^{*}(r)}{d r}=\frac{d B_{2}^{\prime-1}(r)}{d r}=B_{2}^{\prime \prime-1}(\cdot) \equiv \frac{1}{B_{2}^{\prime \prime}\left(q_{2}\right)}
$$

by the inverse function rule.

While the quota price is parametric to the competitive firm, it is of course endogenous to the industry as a whole. The fringe demand for quota at a price $\bar{r}$ is $Q_{2}^{*}(\bar{r})$. If $Q_{2}^{*}(\bar{r})=\Omega-Q_{1}^{*}$ (the residual quota supply to the fringe) then $\bar{r}\left(\Omega-Q_{1}^{*}\right)$ is the marketclearing (equilibrium) quota price. Given the concavity of $B_{2}\left(q_{2}\right)$, the fringe inverse quota demand $r\left(\Omega-Q_{1}\right)$ is decreasing in $\left[\Omega-Q_{1}\right]$, taking a value of zero if $\left[\Omega-Q_{1}\right]$ is just equal to (or greater than) the unconstrained fringe output $B_{2}^{\prime-1}(0)$. Equivalently, $d r(.) / d Q_{1}=-r^{\prime}(\cdot)>0$. 


\section{A dominant firm in the quota market}

Consider, first, a situation in which the dominant firm can exert market power in the quota market but is a price taker in the output market (this might be the case, for example, if other, separately regulated, industries produced an identical good for the same market). Here, the (compliant) dominant firm's short run profit maximisation problem is

$$
\max _{q_{1}, Q_{1}} B_{1}\left(q_{1}\right)-r\left(\Omega-Q_{1}\right)\left[Q_{1}-\bar{Q}_{1}\right] \quad \text { s.t. } \quad q_{1} \geq 0, Q_{1} \geq 0, Q_{1} \geq q_{1},
$$

where $\bar{Q}_{1} \geq 0$ is the initial allocation of quota to the firm. The corresponding Lagrangian is

$$
\mathcal{L}=B_{1}\left(q_{1}\right)-r(\cdot)\left[Q_{1}-\bar{Q}_{1}\right]-\lambda_{1}\left[q_{1}-Q_{1}\right]
$$

and the Kuhn-Tucker conditions for an optimal solution are

$$
\begin{gathered}
\mathcal{L}_{q}=B_{1}^{\prime}\left(q_{1}^{*}\right)-\lambda_{1}^{*} \leq 0, \quad q_{1}^{*} \geq 0, \quad \mathcal{L}_{q} q_{1}^{*}=0, \\
\mathcal{L}_{Q}=-r(\cdot)+r^{\prime}(\cdot)\left[Q_{1}^{*}-\bar{Q}_{1}\right]+\lambda_{1}^{*} \leq 0, \quad Q_{1}^{*} \geq 0, \quad \mathcal{L}_{Q} Q_{1}^{*}=0, \\
\mathcal{L}_{\lambda}=-q_{1}^{*}+Q_{1}^{*} \geq 0, \quad \lambda_{1}^{*} \geq 0, \quad \mathcal{L}_{\lambda} \lambda_{1}^{*}=0 .
\end{gathered}
$$

For $Q_{1}^{*}=q_{1}^{*}>0$, we then have, solving for $\lambda_{1}^{*}$,

$$
B_{1}^{\prime}\left(q_{1}^{*}\right)=R_{1}\left(Q_{1}^{*}\right) \geq 0
$$

where $R_{1}\left(Q_{1}^{*}\right) \equiv r()-.r^{\prime}(\cdot)\left[Q_{1}^{*}-\bar{Q}_{1}\right]$ is the dominant firm's marginal revenue from selling quota if $\bar{Q}_{1}>Q_{1}^{*}$, or its marginal cost of purchasing quota if $\bar{Q}_{1}<Q_{1}^{*}$. Given $r(\cdot)>0, r^{\prime}(\cdot)<0$, expression (6) then implies

$$
\begin{array}{lll}
Q_{1}^{*}>\bar{Q}_{1} \quad & \Rightarrow \quad R_{1}\left(Q_{1}^{*}\right)>r, \quad B_{1}^{\prime}\left(q_{1}^{*}\right)>r, \\
Q_{1}^{*}=\bar{Q}_{1} \quad \Rightarrow \quad R_{1}\left(Q_{1}^{*}\right)=r, & B_{1}^{\prime}\left(q_{1}^{*}\right)=r, \\
Q_{1}^{*}<\bar{Q}_{1} \quad \Rightarrow \quad R_{1}\left(Q_{1}^{*}\right)<r, & B_{1}^{\prime}\left(q_{1}^{*}\right)<r,
\end{array}
$$


and we can therefore state

Result 1. (Hahn) Where the dominant firm is behaving as a monopolist in the quota market $\left(Q_{1}^{*}<\bar{Q}_{1}\right)$, we have $B_{1}^{\prime}\left(q_{1}^{*}\right)<r(\cdot)$, whereas if $Q_{1}^{*}>\bar{Q}_{1}$, we have $B_{1}^{\prime}\left(q_{1}^{*}\right)>r(\cdot)$. Only in the case where $Q_{1}^{*}=\bar{Q}_{1}$ is the market equilibrium quota price the efficient price, where the marginal costs of production are equated across all firms. Otherwise, the quota price faced by the competitive fringe is either too low, so that the competitive firms overproduce relative to the dominant firm, or too high, so that the competitive firms underproduce relative to the dominant firm.

This is the basic (static) efficiency result found by Hahn [7] for the analogous case of a market in pollution permits (see also van Egteren and Weber [5] and Malik [12]).

If the dominant firm finds it profitable to demand quota in excess of its requirement for legal production $\left(Q_{1}^{*}>q_{1}^{*}>0\right)$, then from the complementary slackness condition in (5c) we must have $\lambda_{1}^{*}=0$ so that

$$
B_{1}^{\prime}\left(q_{1}^{*}\right)=R_{1}\left(Q_{1}^{*}\right) \equiv r(\cdot)-r^{\prime}(\cdot)\left[Q_{1}^{*}-\bar{Q}_{1}\right]=0
$$

which, given $r(\cdot)>0$ and $r^{\prime}(\cdot)<0$, requires $Q_{1}^{*}<\bar{Q}_{1}$. Thus we have

Result 2. (Malik) The dominant firm will only demand excess quota if it is initially overendowed with quota to the extent that its marginal revenue from selling quota is zero when $Q_{1}^{*}>q_{1}^{*}$. Here, $B_{1}^{\prime}\left(q_{1}^{*}\right)=0$ implies that the dominant firm's own output is unconstrained.

This is (expressed in slightly different form) equivalent to the result found by Malik [12] 
for a dominant firm in an emissions permit market. Note that, even if $\Omega$ were to exceed the total unconstrained industry output, if the initial allocation of quota to the dominant firm were large enough it could restrict the supply of quota to the competitive fringe and hence restrict the total level of output.

We could also have a $\bar{Q}_{1}$ such that $Q_{1}^{*}=q_{1}^{*}$ is an unconstrained solution to (4), but for any smaller $\bar{Q}_{1}$, the unconstrained firm will be non-compliant. Although a non-compliant dominant firm may have a positive quota demand, we cannot have $Q_{1}^{*}>\bar{Q}_{1}$, i.e., the firm will never be a net purchaser of quota. An unconstrained solution where $Q_{1}^{*}=\bar{Q}_{1}$ is possible, but implies that $r=0$, i.e., if (in the absence of enforcement) the non-compliant firm demands only its initial quota allocation, then this must be such as to leave a residual quota supply to the fringe which equals or exceeds its total capacity. Note that, again in the absence of enforcement, $\bar{Q}_{1}=0$ unambiguously implies $Q_{1}^{*}=0$.

Since, if we allow the firm to be non-compliant, we can in general say that it will cheat wherever it has no incentive to hold excess quota, we have the obvious (and perhaps not entirely trivial) corollary, as noted by Malik [12] in the context of pollution permits, that it is possible for a dominant firm to be "over-endowed" with quota such that it will not violate.

If we assume that the firm is subject to enforcement of its quota compliance, however, we can replace the constraint term in the Lagrangian function with an expected penalty term $\theta_{1}\left(v_{1}\right)$, where $\theta_{1}\left(v_{1}\right)$ is the product of a fine for a violation $v_{1}$ and the firm's (subjective) probability of incurring that fine. We assume that at least one of these two quantities 
is a function of the size of the firm's quota violation, defined in general terms as $v_{1} \equiv$ $v_{1}\left(q_{1}, Q_{1}\right)$. For $q_{1}^{*}>Q_{1}^{*}>0$, we then have the first order conditions

$$
B_{1}^{\prime}\left(q_{1}^{*}\right)=\frac{\partial \theta_{1}\left(v_{1}\right)}{\partial q_{1}}>0
$$

and

$$
R_{1}\left(Q_{1}^{*}\right)=-\frac{\partial \theta_{1}\left(v_{1}\right)}{\partial Q_{1}}>0 .
$$

Subtracting (10) from (9) and rearranging, we obtain the joint decision rule

$$
B_{1}^{\prime}\left(q_{1}^{*}\right)=R_{1}\left(Q_{1}^{*}\right)+\left[\frac{\partial \theta_{1}\left(v_{1}\right)}{\partial q_{1}}+\frac{\partial \theta_{1}\left(v_{1}\right)}{\partial Q_{1}}\right]>0 .
$$

Notice that if the expected penalty is assumed to depend only upon the level violation size $\left(v_{1} \equiv q_{1}-Q_{1}\right)$, as is generally assumed in the pollution permit literature for example, then $\partial \theta_{1}\left(v_{1}\right) / \partial q_{1}=-\partial \theta_{1}\left(v_{1}\right) / \partial Q_{1}=\theta_{1}^{\prime}\left(v_{1}\right)$ and hence we have

$$
B_{1}^{\prime}\left(q_{1}^{*}\right)=R_{1}\left(Q_{1}^{*}\right)
$$

as before, so that $B_{1}^{\prime}\left(q_{1}^{*}\right)=r$ when $Q_{1}^{*}=\bar{Q}_{1}$, as in the case of a compliant firm. If, on the other hand, the expected penalty depends upon the relative size of the violation, i.e., $v_{1} \equiv\left[q_{1}-Q_{1}\right] / Q_{1}\left(\right.$ or $\left.v_{1} \equiv q_{1} / Q_{1}\right){ }^{2}$ then in the first order conditions we will have

$$
\frac{\partial \theta_{1}\left(v_{1}\right)}{\partial q_{1}}=\theta_{1}^{\prime}\left(v_{1}\right) \frac{1}{Q_{1}^{*}}
$$

and

$$
\frac{\partial \theta_{1}\left(v_{1}\right)}{\partial Q_{1}}=-\theta_{1}^{\prime}\left(v_{1}\right) \frac{q_{1}^{*}}{Q_{1}^{* 2}}
$$

so that (10) becomes

$$
B_{1}^{\prime}\left(q_{1}^{*}\right)=R_{1}\left(Q_{1}^{*}\right)+\theta_{1}^{\prime}\left(v_{1}^{*}\right)\left[\frac{1}{Q_{1}^{*}}-\frac{q_{1}^{*}}{Q_{1}^{* 2}}\right]>0 .
$$

\footnotetext{
2 see Hatcher $[8,9]$
} 
Now, $q_{1}^{*}>Q_{1}^{*}$ implies that

$$
0<B_{1}^{\prime}\left(q_{1}^{*}\right)<R_{1}\left(Q_{1}^{*}\right)
$$

With a relative violation argument in the expected penalty function, we therefore have

$$
\begin{aligned}
& Q_{1}^{*}>\bar{Q}_{1} \quad \Rightarrow \quad R_{1}\left(Q_{1}^{*}\right)>r, \quad B_{1}^{\prime}\left(q_{1}^{*}\right) \gtreqless r, \\
& Q_{1}^{*}=\bar{Q}_{1} \quad \Rightarrow \quad R_{1}\left(Q_{1}^{*}\right)=r, \quad B_{1}^{\prime}\left(q_{1}^{*}\right)<r, \\
& Q_{1}^{*}<\bar{Q}_{1} \quad \Rightarrow \quad R_{1}\left(Q_{1}^{*}\right)<r, \quad B_{1}^{\prime}\left(q_{1}^{*}\right)<r,
\end{aligned}
$$

which leads us to

Result 3. When the dominant firm is non-compliant and subject to enforcement, Result 1 (Hahn) continues to hold if and only if the firm's expected penalty depends upon its violation expressed in level terms. If the firm's expectation of a penalty is a function of its violation expressed in relative terms, then production can only be efficiently allocated if the non-compliant firm is a net purchaser of quota.

This result does, however, assume that the fringe is compliant, or, if non-compliant, has expected penalties expressed as a function of level violations, so that $B_{2}^{\prime}\left(q_{2}^{*}\right)=r$. If, for both the dominant firm and the fringe, expected penalties depended upon the relative violation size, then we would have $B_{2}^{\prime}\left(q_{2}^{*}\right)<r$ (see Appendix A) and hence production could potentially be efficiently allocated for any $Q_{1}^{*} \gtreqless \bar{Q}_{1}$.

\section{A dominant firm in both quota and output markets}

Now consider a firm with market dominance in both the quota and output markets (this 
might arise in a situation where the entire output market is supplied by one industry under quota regulation). The (compliant) dominant firm's short run profit maximisation problem can now be written as

$$
\begin{gathered}
\max _{q_{1}, Q_{1}} \quad B_{1}\left(q_{1}, p(\mathbf{q})\right)-r\left(\Omega-Q_{1}, p(\mathbf{q})\right)\left[Q_{1}-\bar{Q}_{1}\right] \\
\text { s.t. } \quad q_{1} \geq 0, Q_{1} \geq 0, Q_{1} \geq q_{1},
\end{gathered}
$$

where $\mathbf{q} \equiv q_{1}+q_{2}$ is the combined output of the dominant firm and the competitive fringe and $p(\mathbf{q})$ is the inverse consumer demand for that output, with, we assume, $p^{\prime}(\mathbf{q})<0$. Note that changes in $p(\mathbf{q})$ impact upon both $B_{1}(\cdot)$ as well as, indirectly through the effect on $B_{2}^{\prime}(\cdot)$, the equilibrium quota price $r(\cdot)$.

The corresponding Lagrangian and the Kuhn-Tucker conditions for an optimum are

$$
\mathcal{L}=B_{1}\left(q_{1}, p(\mathbf{q})\right)-r\left(\Omega-Q_{1}, p(\mathbf{q})\right)\left[Q_{1}-\bar{Q}_{1}\right]-\lambda_{1}\left[q_{1}-Q_{1}\right]
$$

with

$$
\begin{gathered}
\mathcal{L}_{q}=\frac{\partial B_{1}(\cdot)}{\partial q_{1}}+\frac{\partial B_{1}(\cdot)}{\partial p(\mathbf{q})} p^{\prime}(\mathbf{q}) \frac{\partial \mathbf{q}}{\partial q_{1}}-\frac{\partial r(\cdot)}{\partial p(\mathbf{q})} p^{\prime}(\mathbf{q}) \frac{\partial \mathbf{q}}{\partial q_{1}}\left[Q_{1}^{*}-\bar{Q}_{1}\right]-\lambda_{1}^{*} \leq 0 \\
q_{1}^{*} \geq 0, \quad \mathcal{L}_{q} q_{1}^{*}=0 \\
\mathcal{L}_{Q}=\frac{\partial B_{1}(\cdot)}{\partial p(\cdot)} p^{\prime}(\mathbf{q}) \frac{\partial \mathbf{q}}{\partial Q_{1}}-r(\cdot)-\frac{\partial r(\cdot)}{\partial Q_{1}}\left[Q_{1}^{*}-\bar{Q}_{1}\right]-\frac{\partial r(\cdot)}{\partial p(\mathbf{q})} p^{\prime}(\mathbf{q}) \frac{\partial \mathbf{q}}{\partial Q_{1}}\left[Q_{1}^{*}-\bar{Q}_{1}\right]+\lambda_{1}^{*} \leq 0 \\
Q_{1}^{*} \geq 0, \quad \mathcal{L}_{Q} Q_{1}^{*}=0, \quad \\
\mathcal{L}_{\lambda}=-q_{1}^{*}+Q_{1}^{*} \geq 0, \quad \lambda_{1}^{*} \geq 0, \quad \mathcal{L}_{\lambda} \lambda_{1}^{*}=0
\end{gathered}
$$

For $Q_{1}^{*}=q_{1}^{*}>0$, we then have

$$
\frac{\partial B_{1}(\cdot)}{\partial q_{1}}+p^{\prime}(\mathbf{q}) \frac{\partial \mathbf{q}}{\partial q_{1}}\left[q_{1}^{*}-\left[Q_{1}^{*}-\bar{Q}_{1}\right]\right]=\lambda_{1}^{*} \geq 0
$$


and

$$
r(\cdot)+\frac{\partial r(\cdot)}{\partial Q_{1}}\left[Q_{1}^{*}-\bar{Q}_{1}\right]-p^{\prime}(\mathbf{q}) \frac{\partial \mathbf{q}}{\partial Q_{1}}\left[q_{1}^{*}-\left[Q_{1}^{*}-\bar{Q}_{1}\right]\right]=\lambda_{1}^{*} \geq 0,
$$

where we have used $\partial B_{1}(\cdot) / \partial p(\cdot)=q_{1}^{*}$ and $\partial r(\cdot) / \partial p(\mathbf{q})=1 .^{3}$ Note that here $\partial B_{1}(\cdot) / \partial q_{1}$ and $\partial r(\cdot) / \partial Q_{1}$ are equivalent to $B_{1}^{\prime}\left(q_{1}^{*}\right)$ and $-r^{\prime}(\cdot)$ in the previous section.

Solving (18) and (19) for $\lambda_{1}^{*}$, we obtain the joint optimal decision rule

$$
\frac{\partial B_{1}(\cdot)}{\partial q_{1}}+p^{\prime}(\mathbf{q})\left[\frac{\partial \mathbf{q}}{\partial q_{1}}+\frac{\partial \mathbf{q}}{\partial Q_{1}}\right]\left[q_{1}^{*}-\left[Q_{1}^{*}-\bar{Q}_{1}\right]\right]=R_{1}\left(Q_{1}^{*}\right),
$$

where, as before, $R_{1}\left(Q_{1}^{*}\right) \equiv r(\cdot)+\partial r(\cdot) / \partial Q\left[Q_{1}^{*}-\bar{Q}_{1}\right]$. The additional term on the LHS of (20) captures the firm's net marginal impact upon its revenues from output as well as revenues from, or costs of, quota trade, through the effect of its own output and quota demand upon the total industry output $\mathbf{q}$ and hence the market price $p(\mathbf{q})$.

In order to examine the dominant firm's impact upon q, note firstly that

$$
\frac{\partial \mathbf{q}}{\partial q_{1}}=\frac{\partial q_{1}}{\partial q_{1}}+\frac{\partial q_{2}}{\partial q_{1}}=1+\frac{\partial q_{2}}{\partial q_{1}}
$$

where $\partial q_{2} / \partial q_{1}$ is the firm's conjectural derivative for the output of the competitive fringe in relation to its own output. If the output of the fringe is constrained by its residual quota supply, i.e., $q_{2}=Q_{2}=\Omega-Q_{1}$, then we can assume $\partial q_{2} / \partial q_{1}=0$ (Cournot) and therefore $\partial \mathbf{q} / \partial q_{1}=1$. Similarly,

$$
\frac{\partial \mathbf{q}}{\partial Q_{1}}=\frac{\partial q_{1}}{\partial Q_{1}}+\frac{\partial q_{2}}{\partial Q_{1}}=0+\frac{\partial q_{2}}{\partial Q_{1}}
$$

Here, given market clearing in the quota market, a compliant fringe implies $\partial q_{2} / \partial Q_{1}=$ $\partial Q_{2} / \partial Q_{1}=-1$, so that $\partial \mathbf{q} / \partial Q_{1}=-1$.

\footnotetext{
3 Assuming that the fringe is compliant, we have $r(\cdot)=B_{2}^{\prime}\left(q_{2}\right) \equiv p(\mathbf{q})-c_{2}^{\prime}\left(q_{2}\right)$ and hence $\partial r(\cdot) / \partial p(\mathbf{q})=1$.
} 
If $\partial \mathbf{q} / \partial q_{1}=1$ and $\partial \mathbf{q} / \partial Q_{1}=-1$, then $\partial \mathbf{q} / \partial q_{1}+\partial \mathbf{q} / \partial Q_{1}=0$ and (20) collapses to

$$
\frac{\partial B_{1}(\cdot)}{\partial q_{1}}=R_{1}\left(Q_{1}^{*}\right)
$$

as in the case of a firm with dominance only in the quota market. Although, given a compliant fringe, $Q_{1}^{*}=q_{1}^{*}$ implies that the dominant firm has no net effect upon total industry output (which remains equal to $\Omega$ ), note that only where $q_{1}^{*}=\left[Q_{1}^{*}-\bar{Q}_{1}\right]>0$ are the first order conditions equivalent to those for a firm with dominance only in the quota market (unless $\bar{Q}_{1}=0$, however, this would imply $q_{1}^{*}>Q_{1}^{*}$, i.e., cheating). Note, also, that here we could not have $\partial B_{1}(\cdot) / \partial q_{1}=R_{1}\left(Q_{1}^{*}\right)=0$, since $R_{1}\left(Q_{1}^{*}\right)=0$ requires $\left[Q_{1}^{*}-\bar{Q}_{1}\right]<0$

For an unconstrained solution to the dominant firm's problem $\left(q_{1}^{*} \gtreqless Q_{1}^{*}\right)$, we require $\lambda_{1}^{*}=0$ in the Kuhn-Tucker conditions and hence, from (18) and (19), and given $\partial \mathbf{q} / \partial q_{1}=1$ and $\partial \mathbf{q} / \partial Q_{1}=-1$, we have

$$
\frac{\partial B_{1}(\cdot)}{\partial q_{1}}+p^{\prime}(\mathbf{q}) q_{1}^{*}=p^{\prime}(\mathbf{q})\left[Q_{1}^{*}-\bar{Q}_{1}\right] \gtreqless 0
$$

and

$$
r(\cdot)+\left[\frac{\partial r(\cdot)}{\partial Q_{1}}-p^{\prime}(\mathbf{q})\right]\left[Q_{1}^{*}-\bar{Q}_{1}\right]=-p^{\prime}(\mathbf{q}) q_{1}^{*}>0,
$$

where we have rearranged terms in order more clearly to distinguish the marginal impacts on revenues from output and on revenues from (costs of) quota selling (buying). From (21) we can see that the optimal net marginal benefit of output could now be negative if it is profitable to purchase quota in order to support the output price. In the case where $Q_{1}^{*}=\bar{Q}_{1}$, notice, the dominant firm produces where

$$
\frac{\partial B_{1}(\cdot)}{\partial q_{1}}+p^{\prime}(\mathbf{q}) q_{1}^{*}=0
$$

which is equivalent to the usual rule for a monopoly producer. At the same time, we would 
have $r(\cdot)=-p^{\prime}(\mathbf{q}) q_{1}^{*}$ and hence $\partial B_{1}(\cdot) / \partial q_{1}=r(\cdot)$, so that total output, although it may not equal $\Omega$, is efficiently produced (given, as before, certain assumptions about the fringe). Here, the dominant firm's initial allocation is such that it does not exercise market power in the quota market, although it does in the output market. In this case, Hahn's [7] result still holds, even where $Q_{1}^{*}<q_{1}^{*}$.

From (21) and (22), we can observe that, for an unconstrained solution to the firm's problem, we have the condition

$$
\frac{\partial B_{1}(\cdot)}{\partial q_{1}}=R_{1}\left(Q_{1}^{*}\right)=p^{\prime}(\mathbf{q})\left[\left[Q_{1}^{*}-\bar{Q}_{1}\right]-q_{1}^{*}\right]>0,
$$

where we know that $\partial B_{1}(\cdot) / \partial q_{1}=R_{1}\left(Q_{1}^{*}\right)>0$, since, given $r(\cdot)>0, R_{1}\left(Q_{1}^{*}\right) \leq 0$ requires $\left[Q_{1}^{*}-\bar{Q}_{1}\right]<0$ which would still imply $p^{\prime}(\mathbf{q})\left[\left[Q_{1}^{*}-\bar{Q}_{1}\right]-q_{1}^{*}\right]>0$. Condition (23) leads directly to

Proposition 1. If a firm has market dominance in both the quota market and the output market, it may be voluntarily compliant, or even hold excess quota in order to support the market price for its output, provided that its initial quota endowment is strictly positive. This holds even if the firm becomes a net purchaser of quota as a result.

Proof. Given $p^{\prime}(\mathbf{q})<0$, in $(23)$ we require $\left[\left[Q_{1}^{*}-\bar{Q}_{1}\right]-q_{1}^{*}\right]<0$ and hence $\left[Q_{1}^{*}-\bar{Q}_{1}\right]<$ $q_{1}^{*}$. This immediately excludes the possibility that a dominant firm will be compliant when its initial allocation $\bar{Q}_{1}$ is zero, but otherwise $Q_{1}^{*} \geq q_{1}^{*}$ does not now require $\bar{Q}_{1}>Q_{1}^{*}$, as is the case when the dominant firm has market power only in the quota market.

Note that the condition $\bar{Q}_{1}>0$ ensures that, if the dominant firm is a net purchaser of 
quota, the amount of quota purchased is strictly less than output. Rearranging the RHS of (23), we can also observe that if the firm is holding excess quota we will always have

$$
\left[Q_{1}^{*}-q_{1}^{*}\right]<\bar{Q}_{1}
$$

i.e., the amount of excess quota held (if any) is strictly less than the firm's initial allocation.

Proposition 1 contradicts the finding of Anderson [1] that, if the dominant firm were a net purchaser of quota, it would never be profitable for it to restrict its output "because any increase in the price of the marketable output will be transferred into an increase in the purchase price (of quota)" (p.296). Anderson's conclusion derives from his assumption that, in the monopsony case, the firm's initial quota allocation was zero so that, as we have seen, the firm will indeed not hold excess quota. More recently, Anderson [2] revises this earlier conclusion, although without further formal analysis of the problem. ${ }^{4}$ As we have seen, the dominant firm will not freely even match its quota demand to its output if the initial quota allocation is zero, which we can state as

Corollary 1. If the dominant firm's initial quota allocation is zero, it will unambiguously cheat.

Proof. If $\bar{Q}_{1}=0$ in (23), we must have $Q_{1}^{*}<q_{1}^{*}$.

While $Q_{1}^{*}<q_{1}^{*}$ is the only possible unconstrained solution to (16) if $\bar{Q}_{1}=0$, however, it is

\footnotetext{
4 The primary focus of Anderson's [2] paper is rather different to this one. He distinguishes between what he terms "traditional" or "capacity-based" market power and "permit-based" market power, which he treats separately. The primary focus of his analysis is then the possibility that one quota-holding firm might find it profitable to lease the productive capacity of other firms in order to control the market supply of the good (fish).
} 
also an unconstrained solution if $\bar{Q}_{1}>0$. If, in (21) and (22), $\bar{Q}_{1}=0$, then we will have

$$
\frac{\partial B_{1}(\cdot)}{\partial q_{1}}+p^{\prime}(\mathbf{q}) q_{1}^{*}=p^{\prime}(\mathbf{q}) Q_{1}^{*} \leq 0
$$

and

$$
r(.)+\frac{\partial r(\cdot)}{\partial Q_{1}} Q_{1}^{*}=p^{\prime}(\mathbf{q})\left[Q_{1}^{*}-q_{1}^{*}\right]>0 .
$$

Here, notice, we cannot rule out $Q_{1}^{*}>0$ even where $r()>$.0 , i.e., the firm may now purchase quota even if it is not subject to any enforcement.

In summary, if the initial endowment of quota to the dominant firm is greater than zero, the firm may choose to withhold quota from the market or to cheat, or indeed to match quota and output. The outcome will be parameter-specific, depending upon the relative production capacities of the dominant firm and the competitive fringe as well as the relative slopes of the consumer inverse demand curve for the industry output and the (fringe) inverse quota demand curve. If, however, the dominant firm's initial quota allocation is zero, it will unambiguously be non-compliant, although even in the absence of enforcement the firm's quota demand may still be positive. Here, $Q_{1}^{*}<q_{1}^{*}$ implies that total output exceeds $\Omega$ and hence the output price is lower than if the firm is compliant.

If the firm is non-compliant, on the other hand, we can assume as before that it is subject to enforcement and expects to incur a penalty for a violation. Then, still letting $\partial \mathbf{q} / \partial q_{1}=1$ and $\partial \mathbf{q} / \partial Q_{1}=-1$, for $Q_{1}^{*}<q_{1}^{*}$ we have the first order conditions

$$
\frac{\partial B_{1}(\cdot)}{\partial q_{1}}+p^{\prime}(\mathbf{q})\left[q_{1}^{*}-\left[Q_{1}^{*}-\bar{Q}_{1}\right]\right]=\frac{\partial \theta_{1}\left(v_{1}\right)}{\partial q_{1}}>0
$$

and

$$
R_{1}\left(Q_{1}^{*}\right)+p^{\prime}(\mathbf{q})\left[q_{1}^{*}-\left[Q_{1}^{*}-\bar{Q}_{1}\right]\right]=-\frac{\partial \theta_{1}\left(v_{1}\right)}{\partial Q_{1}}>0
$$


and hence

$$
\frac{\partial B_{1}(\cdot)}{\partial q_{1}}=R_{1}\left(Q_{1}^{*}\right)+\left[\frac{\partial \theta_{1}\left(v_{1}\right)}{\partial q_{1}}+\frac{\partial \theta_{1}\left(v_{1}\right)}{\partial Q_{1}}\right]>0
$$

as we had previously. Again, Hahn's [7] result can hold for a non-compliant firm (depending upon our assumptions about the behaviour of the fringe) if and only if the violation in the expected penalty function is expressed in level terms, i.e., $v_{1} \equiv q_{1}-Q_{1}$.

\section{A non-compliant fringe}

We have so far assumed that the competitive fringe is compliant. We now briefly consider how our analysis of the dominant firm's behaviour changes if we relax this assumption. Non-compliance in the fringe has two effects in our model. Firstly, as noted by Malik [12] in the context of pollution permits, non-compliance affects the elasticity of the fringe's (inverse) quota demand. In Malik's model, fringe non-compliance renders the fringe firms' permit demands (everywhere) more elastic and hence the fringe inverse demand (everywhere) less elastic. This result does, however, depend upon his modelling of fringe firms' expected penalties as a function of their violations expressed in level terms. If expected penalties in the fringe are instead expressed as a function of relative violations, the effect upon the elasticity of quota demand varies with the quota price (see Appendix A). In this case, non-compliant quota demands are more elastic at relatively low or high quota prices, but less elastic at intermediate quota prices. A more, rather than less, elastic fringe inverse quota demand would result in an increase in the dominant firm's quota market monopoly power, rather than the reduction found by Malik. ${ }^{5}$

\footnotetext{
5 As a result, Malik [12] finds that there may be net social benefits from non-compliance in the fringe. This would not be the case, however, if the fringe inverse quota demand were to become more, rather than less, elastic through non-compliance.
} 
Secondly, in our analysis of a dominant firm with both quota and output market power, recall that the assumption of a compliant fringe enabled us to assume that $\partial r(\cdot) / \partial p(\mathbf{q})=$ 1 and that $\partial \mathbf{q} / \partial q_{1}=-\partial \mathbf{q} / \partial Q_{1}=1$, so that in the decision rule

$$
\frac{\partial B_{1}(\cdot)}{\partial q_{1}}+p^{\prime}(\mathbf{q})\left[\frac{\partial \mathbf{q}}{\partial q_{1}}+\frac{\partial r(\cdot)}{\partial p(\mathbf{q})} \cdot \frac{\partial \mathbf{q}}{\partial Q_{1}}\right]\left[q_{1}^{*}-\left[Q_{1}^{*}-\bar{Q}_{1}\right]\right]=R_{1}\left(Q_{1}^{*}\right)
$$

the first bracketed term on the LHS was equal to zero and the expression collapsed to

$$
\frac{\partial B_{1}(\cdot)}{\partial q_{1}}=R_{1}\left(Q_{1}^{*}\right)
$$

as for a firm with quota market power alone.

If expected penalties in a non-compliant fringe are assumed to depend upon the level violation size, we will still have $B_{2}^{\prime}\left(q_{2}^{*}\right)=r(\cdot)$ and hence $\partial r(\cdot) / \partial p(\mathbf{q})=\partial B_{2}^{\prime}\left(q_{2}^{*}\right) / \partial p(\mathbf{q})=1$ as before. If expected penalties in the fringe are assumed to depend upon the relative size of violations, then, as we show in Appendix A, we will have $B_{2}^{\prime}\left(q_{2}^{*}\right)<r(\cdot)$ and therefore we cannot assume that $\partial r(\cdot) / \partial p(\mathbf{q})=1$. Nevertheless, we would still expect that $\partial r(\cdot) / \partial p(\mathbf{q})>0$ and hence the sign of $\partial \mathbf{q} / \partial Q_{1}$ to be unchanged. Looking now at the (unconstrained) condition for $Q_{1}^{*}$ written out in full

$$
R_{1}\left(Q_{1}^{*}\right)=-p^{\prime}(\mathbf{q}) \frac{\partial \mathbf{q}}{\partial Q_{1}}\left[\left[Q_{1}^{*}-\bar{Q}_{1}\right]-q_{1}^{*}\right]
$$

we can see, provided we still have $\partial \mathbf{q} / \partial Q_{1}=\partial q_{2} / \partial Q_{1}<0$, that $R_{1}\left(Q_{1}^{*}\right)$ takes the opposite sign to $\left[\left[Q_{1}^{*}-\bar{Q}_{1}\right]-q_{1}^{*}\right]$. However, it is then apparent that we must have $R_{1}\left(Q_{1}^{*}\right)>$ 0 and hence $\left[\left[Q_{1}^{*}-\bar{Q}_{1}\right]-q_{1}^{*}\right]<0$ as before (since we cannot have $R_{1}\left(Q_{1}^{*}\right)<0$ and $\left.\left[\left[Q_{1}^{*}-\bar{Q}_{1}\right]-q_{1}^{*}\right]>0\right)$. If $\partial q_{2} / \partial Q_{1}=0$, however, then $R_{1}\left(Q_{1}^{*}\right)=0$, which again requires $\left[Q_{1}^{*}-\bar{Q}_{1}\right]<0$ and hence $\left[\left[Q_{1}^{*}-\bar{Q}_{1}\right]-q_{1}^{*}\right]<0$. A conjectural derivative of $\partial q_{2} / \partial Q_{1}>0$, on the other hand, implies that the dominant firm expects the fringe to increase its output in response to a decrease in its residual quota supply, which we can dismiss as perverse. 
In the corresponding condition for $q_{1}^{*}$

$$
\frac{\partial B_{1}(\cdot)}{\partial q_{1}}=p^{\prime}(\mathbf{q}) \frac{\partial \mathbf{q}}{\partial q_{1}}\left[\left[Q_{1}^{*}-\bar{Q}_{1}\right]-q_{1}^{*}\right]
$$

we can therefore assume that $\left[\left[Q_{1}^{*}-\bar{Q}_{1}\right]-q_{1}^{*}\right]<0$. Here, fringe non-compliance does not change the resultant positive sign of the expression provided $\partial q_{2} / \partial q_{1}>-1$. If $\partial q_{2} / \partial q_{1}=$ -1 (the usual competitive conjecture) then $\partial \mathbf{q} / \partial q_{1}=0$ and hence $\partial B_{1}(\cdot) / \partial q_{1}=0$, as for a dominant firm with no market power in the output market. If $\partial q_{2} / \partial q_{1}<-1$, on the other hand, we will have $\partial \mathbf{q} / \partial q_{1}<0$ and hence $\partial B_{1}(\cdot) / \partial q_{1}<0$.

In summary, in the case of a dominant firm with both quota and output market power, fringe non-compliance does not change the sign of $\left[\left[Q_{1}^{*}-\bar{Q}_{1}\right]-q_{1}^{*}\right]$ in the conditions for unconstrained profit maximisation and therefore does not substantially change our conclusions about the dominant firm's behaviour, although at the margins it will affect the firm's choices of $q_{1}^{*}$ and $Q_{1}^{*}$ (and we can no longer assume $\partial B_{1}(\cdot) / \partial q_{1}=R_{1}\left(Q_{1}^{*}\right)$ as before).

\section{Conclusion}

We have shown that an unconstrained firm with dominance in both quota and output markets may hold excess quota in order to support the output price, even if it is a net buyer of quota, provided that its initial quota allocation is non-zero. Even in the absence of enforcement, therefore, the dominant firm may find it profitable to comply or to overcomply with its quota rather than to cheat. The outcome is parameter-specific, but the amount of any excess quota held will be strictly less than the firm's initial quota allocation 
(this could provide a general "rule of thumb" for the avoidance of output restriction under quotas). If the firm's initial quota allocation is zero, on the other hand, it will always cheat, although, even in the absence of enforcement, a non-compliant firm may still purchase some quota.

Hahn's [7] efficiency result holds in all cases for both compliant and non-compliant firms except where expected penalties are not modelled as a function of level violations... 


\section{Appendix A}

For a non-compliant price-taking firm, the short run (risk-neutral) expected profit maximisation problem is

$$
\max _{q_{2}, Q_{2}} B_{2}\left(q_{2}\right)-r Q_{2}-\theta_{2}\left(v_{2}\right) \quad \text { s.t. } \quad q_{2} \geq 0, Q_{2} \geq 0,
$$

where the expected fine $\theta_{2}\left(v_{2}\right)$ is defined as before. From the Lagrangian, the KuhnTucker conditions for an optimum are

$$
\begin{gathered}
\mathcal{L}_{q}=B_{2}^{\prime}\left(q_{2}^{*}\right)-\frac{\partial \theta_{2}\left(v_{2}^{*}\right)}{\partial q_{2}} \leq 0, \quad q_{2}^{*} \geq 0, \quad \mathcal{L}_{q} q_{2}^{*}=0 \\
\mathcal{L}_{Q}=-r-\frac{\partial \theta_{2}\left(v_{2}^{*}\right)}{\partial Q_{2}} \leq 0, \quad Q_{2}^{*} \geq 0, \quad \mathcal{L}_{Q} Q_{2}^{*}=0
\end{gathered}
$$

If the violation is expressed in level terms, i.e., $v_{2} \equiv q_{2}-Q_{2}$, then $\partial \theta_{2}\left(v_{2}^{*}\right) / \partial q_{2}=$ $-\partial \theta_{2}\left(v_{2}^{*}\right) / \partial Q_{2}=\theta_{2}^{\prime}\left(v_{2}^{*}\right)$ and hence for $q_{2}^{*}>Q_{2}^{*}>0$ we have

$$
B_{2}^{\prime}\left(q_{2}^{*}\right)=r
$$

as for a compliant firm (Malik [11]).

Consider, however, the case where the expected penalty is a function of the firm's relative violation of its quota demand. Thus let $v_{2} \equiv q_{2} / Q_{2}$, with $\theta_{2}^{\prime \prime}\left(v_{2}\right) \geq 0$. For $q_{2}^{*}>Q_{2}^{*}>0$, we then have the first-order necessary conditions

$$
B_{2}^{\prime}\left(q_{2}^{*}\right)=\frac{\partial \theta_{2}\left(v_{2}^{*}\right)}{\partial q_{2}}=\theta_{2}^{\prime}\left(v_{2}^{*}\right) \frac{1}{Q_{2}^{*}(r)}
$$

and

$$
r=-\frac{\partial \theta_{2}\left(v_{2}^{*}\right)}{\partial Q_{2}}=\theta_{2}^{\prime}\left(v_{2}^{*}\right) \frac{q_{2}^{*}(r)}{Q_{2}^{*}(r)^{2}} .
$$

If we solve (A-3) and (A-4) for $\theta_{2}^{\prime}\left(v_{2}^{*}\right)$, we can find the "violation ratio" identity

$$
\frac{Q_{2}^{*}(r)}{q_{2}^{*}(r)}=\frac{B_{2}^{\prime}\left(q_{2}^{*}\right)}{r} \leq 1,
$$


which, following Hatcher [8], we will henceforth denote by $\sigma_{2}^{*}(r)$. Here, a value of $\sigma_{2}^{*}(r)=$ 1 obviously indicates compliance. Given $Q_{2}^{*}(r)=\sigma_{2}^{*}(r) q_{2}^{*}(r)$, we can then find the slope of the quota demand curve as

$$
\frac{d Q_{2}^{*}(r)}{d r}=\sigma_{2}^{*}(r) \frac{d q_{2}^{*}(r)}{d r}+\frac{Q_{2}^{*}(r)}{\sigma_{2}^{*}(r)} \cdot \frac{d \sigma_{2}^{*}(r)}{d r}
$$

Similarly, from $B_{2}^{\prime}\left(q_{2}^{*}\right)=\sigma_{2}^{*}(r) r$, we can find

$$
B_{2}^{\prime \prime}\left(q_{2}^{*}\right) \frac{d q_{2}^{*}(r)}{d r}=\sigma_{2}^{*}(r)+r \frac{d \sigma_{2}^{*}(r)}{d r}
$$

and hence

$$
\frac{d q_{2}^{*}(r)}{d r}=B_{2}^{\prime \prime-1}(\cdot)\left[\sigma_{2}^{*}(r)+r \frac{d \sigma_{2}^{*}(r)}{d r}\right]
$$

where, by the inverse function rule, $B_{2}^{\prime \prime-1}(.) \equiv 1 / B_{2}^{\prime \prime}\left(q_{2}\right)<0$ is the slope of the inverse of the firm's marginal benefit in output function $B_{2}^{\prime}\left(q_{2}\right)$. Substituting from (A-7) into (A-6) we obtain

$$
\frac{d Q_{2}^{*}(r)}{d r}=B_{2}^{\prime \prime-1}(\cdot)\left[\sigma_{2}^{*}(r)^{2}+\sigma_{2}^{*}(r) r \frac{d \sigma_{2}^{*}(r)}{d r}\right]+\frac{Q_{2}^{*}(r)}{\sigma_{2}^{*}(r)} \cdot \frac{d \sigma_{2}^{*}(r)}{d r} .
$$

For a compliant fringe firm, notice, $\sigma_{2}^{*}(r)=1$ and $d \sigma_{2}^{*}(r) / d r=0$ everywhere, so that (A-8) collapses to

$$
\frac{d Q_{2}^{*}(r)}{d r}=B_{2}^{\prime \prime-1}(\cdot)<0
$$

as we would expect.

In order to interpret expression (A-8), we need to be able to sign $d \sigma_{2}^{*}(r) / d r$ for a noncompliant firm. Although, by definition, non-compliance implies that we must have $d \sigma_{2}^{*}(r) / d r<0$ around $r=0$ (where we assume there is no incentive to cheat and therefore $\sigma_{2}^{*}(r)=1$ ), we cannot, a priori, be sure about the sign of the derivative as the quota price increases further. To examine $d \sigma_{2}^{*}(r) / d r$ we must turn to the comparative statics of the problem. 
If we totally differentiate the first order conditions (A-2a) and (A-2b) with respect to $q_{2}$, $Q_{2}$ and $r$, we obtain

$$
\mathcal{L}_{q q} d q_{2}^{*}(r)+\mathcal{L}_{q Q} d Q_{2}^{*}(r)=0
$$

and

$$
\mathcal{L}_{Q q} d q_{2}^{*}(r)+\mathcal{L}_{Q Q} d Q_{2}^{*}(r)=d r
$$

which we can rearrange and write in matrix form as

Using Cramer's Rule, we can then find

$$
\left[\begin{array}{cc}
\mathcal{L}_{q q} & \mathcal{L}_{q Q} \\
\mathcal{L}_{Q q} & \mathcal{L}_{Q Q}
\end{array}\right]\left[\begin{array}{c}
\frac{d q_{2}^{*}(r)}{d r} \\
\frac{d Q_{2}^{*}(r)}{d r}
\end{array}\right]=\left[\begin{array}{l}
0 \\
1
\end{array}\right]
$$

$$
\frac{d q_{2}^{*}(r)}{d r}=\frac{-\mathcal{L}_{q Q}}{|H|}<0
$$

and

$$
\frac{d Q_{2}^{*}(r)}{d r}=\frac{\mathcal{L}_{q q}}{|H|}<0
$$

where $|H|=\mathcal{L}_{q q} \mathcal{L}_{Q Q}-\mathcal{L}_{q Q}^{2}>0$, together with

$$
\mathcal{L}_{q q}=B_{2}^{\prime \prime}\left(q_{2}^{*}\right)-\frac{\partial^{2} \theta_{2}\left(v_{2}^{*}\right)}{\partial q_{2}^{2}}=B_{2}^{\prime \prime}\left(q_{2}^{*}\right)-\theta_{2}^{\prime \prime}\left(v_{2}^{*}\right) \frac{1}{Q_{2}^{*}(r)^{2}}<0
$$

and

$$
\mathcal{L}_{q Q}=\mathcal{L}_{Q q}=-\frac{\partial^{2} \theta_{2}\left(v_{2}^{*}\right)}{\partial q_{2} \partial Q_{2}}=\theta_{2}^{\prime}\left(v_{2}^{*}\right) \frac{1}{Q_{2}^{*}(r)^{2}}+\theta_{2}^{\prime \prime}\left(v_{2}^{*}\right) \frac{q_{2}^{*}(r)}{Q_{2}^{*}(r)^{3}}>0
$$

Given $\sigma_{2}^{*}(r) \equiv Q_{2}^{*}(r) / q_{2}^{*}(r)$, it is then straightforward to find

$$
\frac{d \sigma_{2}^{*}(r)}{d r}=\frac{1}{q_{2}^{*}(r)}\left[\frac{d Q_{2}^{*}(r)}{d r}-\sigma_{2}^{*}(r) \frac{d q_{2}^{*}(r)}{d r}\right],
$$


where, using (A-11) and (A-12), we can evaluate the expression in brackets as

$$
\begin{aligned}
& \frac{\mathcal{L}_{q q}}{|H|}+\sigma_{2}^{*}(r) \frac{\mathcal{L}_{q Q}}{|H|} \\
& =\frac{1}{|H|}\left[B_{2}^{\prime \prime}\left(q_{2}^{*}\right)-\theta_{2}^{\prime \prime}\left(v_{2}^{*}\right) \frac{1}{Q_{2}^{*}(r)^{2}}\right]+\sigma_{2}^{*}(r) \frac{1}{|H|}\left[\theta_{2}^{\prime}\left(v_{2}^{*}\right) \frac{1}{Q_{2}^{*}(r)^{2}}+\theta_{2}^{\prime \prime}\left(v_{2}^{*}\right) \frac{q_{2}^{*}(r)}{Q_{2}^{*}(r)^{3}}\right] \\
& =\frac{1}{|H|}\left[B_{2}^{\prime \prime}\left(q_{2}^{*}\right)+\sigma_{2}^{*}(r) \theta_{2}^{\prime}\left(v_{2}^{*}\right) \frac{1}{Q_{2}^{*}(r)^{2}}\right] \gtreqless 0 .
\end{aligned}
$$

The sign of (A-15) therefore depends upon the sign of (A-16), in which the first term in the bracketed expression is negative while the second term is positive. If, as stated previously, around $r=0$ we have $d \sigma_{2}^{*}(r) / d r<0$, this implies that here

$$
\left|B_{2}^{\prime \prime}\left(q_{2}^{*}\right)\right|>\left|\sigma_{2}^{*}(r) \theta_{2}^{\prime}\left(v_{2}^{*}\right) \frac{1}{Q_{2}^{*}(r)^{2}}\right| .
$$

Given $d Q_{2}^{*}(r) / d r<0$, however, at some higher quota price the quota demand must be reduced to the point where we have

$$
\left|B_{2}^{\prime \prime}\left(q_{2}^{*}\right)\right|<\left|\sigma_{2}^{*}(r) \theta_{2}^{\prime}\left(v_{2}^{*}\right) \frac{1}{Q_{2}^{*}(r)^{2}}\right|
$$

and hence $d \sigma_{2}^{*}(r) / d r>0$, since $\lim _{Q_{2}^{*} \rightarrow 0} 1 / Q_{2}^{*}(r)^{2}=\infty$. We can then infer that there is some intermediate quota price $\tilde{r}$ at which $d \sigma_{2}^{*}(r) / d r=0$, which implies a minimum value of $\sigma_{2}^{*}(r)$ and hence a maximum relative violation. We can, therefore, state

Result A1. When expected penalties are a function of relative quota violations, the violation rate is initially increasing in the quota price, but reaches a maximum and then declines as the quota price increases further.

We can now evaluate the slope expression (A-8), firstly at $r=0$. Here we assume that $\sigma_{2}^{*}(r)=1$ and $d \sigma_{2}^{*}(r) / d r<0$, so that

$$
\left.\frac{d Q_{2}^{*}(r)}{d r}\right|_{r=0}=B_{2}^{\prime \prime-1}(.)+Q_{2}^{*}(r) \frac{d \sigma_{2}^{*}(r)}{d r}<B_{2}^{\prime \prime-1}(\cdot) .
$$


At $r=0$, therefore, the non-compliant quota demand curve is more elastic than the compliant quota demand curve. At some arbitrarily high quota price, $Q_{2}^{*} \rightarrow 0$ and hence $d \sigma_{2}^{*}(r) / d r \rightarrow+\infty$, so that

$$
\left.\frac{d Q_{2}^{*}(r)}{d r}\right|_{Q_{2}^{*}=0}=B_{2}^{\prime \prime-1}(\cdot)\left[\sigma_{2}^{*}(r)^{2}+r \frac{d \sigma_{2}^{*}(r)}{d r}\right]<B_{2}^{\prime \prime-1}(\cdot),
$$

i.e., the non-compliant quota demand is again more elastic. However, as we have seen, there is some intermediate quota price $\tilde{r}$ at which $\sigma_{2}^{*}(r)<1$ and $d \sigma_{2}^{*}(r) / d r=0$ and hence

$$
\left.\frac{d Q_{2}^{*}(r)}{d r}\right|_{r=\tilde{r}}=B_{2}^{\prime \prime-1}(\cdot) \sigma_{2}^{*}(r)^{2}>B_{2}^{\prime \prime-1}(\cdot)
$$

Here, where the relative violation is at a maximum, the non-compliant quota demand curve is unambiguously less elastic than that of an otherwise identical compliant firm. Thus we have

Result A2. When expected penalties are a function of relative quota violations, the noncompliant quota demand is more elastic than the compliant quota demand at very low or very high quota prices, but is less elastic at intermediate quota prices.

This contrasts with the finding in Hatcher [8], where it was implicitly assumed, erroneously, that $d \sigma_{2}^{*}(r) / d r=0$ everywhere and hence non-compliant quota demands were always less elastic.

Result A2 implies that the non-compliant quota demand curve intersects the compliant quota demand curve, as suggested by Hatcher [8]. We can examine this by introducing a parameter (or state variable) $\Phi$ to represent the regulator's enforcement effort, so that 
$\theta_{2} \equiv \theta_{2}\left(v_{2} ; \Phi\right)$. We then assume that increasing $\Phi$, all else equal, increases the slope of the expected penalty function, i.e., $\partial \theta_{2}^{\prime}(\cdot) / \partial \Phi>0$. Now, if we totally differentiate the first order conditions with respect to $q_{2}, Q_{2}$ and $\Phi$, we obtain

$$
\mathcal{L}_{q q} d q_{2}^{*}(\cdot)+\mathcal{L}_{q Q} d Q_{2}^{*}(\cdot)=\frac{\partial \theta_{2}^{\prime}(\cdot)}{\partial \Phi} \cdot \frac{1}{Q_{2}^{*}(\cdot)} d \Phi
$$

and

$$
\mathcal{L}_{Q q} d q_{2}^{*}(\cdot)+\mathcal{L}_{Q Q} d Q_{2}^{*}(\cdot)=-\frac{\partial \theta_{2}^{\prime}(\cdot)}{\partial \Phi} \cdot \frac{q_{2}^{*}(\cdot)}{Q_{2}^{*}(\cdot)^{2}} d \Phi,
$$

which we can rewrite in matrix form as

$$
\left[\begin{array}{cc}
\mathcal{L}_{q q} & \mathcal{L}_{q Q} \\
\mathcal{L}_{Q q} & \mathcal{L}_{Q Q}
\end{array}\right]\left[\begin{array}{c}
\frac{d q_{2}^{*}(\cdot)}{d \Phi} \\
\frac{d Q_{2}^{*}(\cdot)}{d \Phi}
\end{array}\right]=\left[\begin{array}{c}
\frac{\partial \theta_{2}^{\prime}(\cdot)}{\partial \Phi} \cdot \frac{1}{Q_{2}^{*}(\cdot)} \\
-\frac{\partial \theta_{2}^{\prime}(\cdot)}{\partial \Phi} \cdot \frac{q_{2}^{*}(\cdot)}{Q_{2}^{*}(\cdot)^{2}}
\end{array}\right]
$$

By Cramer's Rule we can then find

$$
\begin{aligned}
\frac{d Q_{2}^{*}(\cdot)}{d \Phi} & =\frac{-\mathcal{L}_{q q} \frac{\partial \theta_{2}^{\prime}(\cdot)}{\partial \Phi} \cdot \frac{q_{2}^{*}(\cdot)}{Q_{2}^{*}(\cdot)^{2}}-\mathcal{L}_{q Q} \frac{\partial \theta_{2}^{\prime}(\cdot)}{\partial \Phi} \cdot \frac{1}{Q_{2}^{*}(\cdot)}}{|H|} \\
& =-\frac{\partial \theta_{2}^{\prime}(\cdot)}{\partial \Phi} \cdot \frac{q_{2}^{*}(\cdot)}{Q_{2}^{*}(\cdot)^{2}} \cdot \frac{\left[\mathcal{L}_{q q}+\sigma_{2}^{*}(\cdot) \mathcal{L}_{q Q}\right]}{|H|}
\end{aligned}
$$

where, from (A-15),

$$
\frac{\left[\mathcal{L}_{q q}+\sigma_{2}^{*}(\cdot) \mathcal{L}_{q Q}\right]}{|H|}=\frac{d Q_{2}^{*}(r)}{d r}-\sigma_{2}^{*}(r) \frac{d q_{2}^{*}(r)}{d r} \gtreqless 0 .
$$

Given $\partial \theta_{2}^{\prime}(\cdot) / \partial \Phi>0$, we can see that $d Q_{2}^{*}(\cdot) / d \Phi$ always takes the opposite sign to $d \sigma_{2}^{*}(\cdot) / d r$. Where the violation rate is increasing in the quota price, therefore, increasing enforcement increases quota demand, but where the violation rate is decreasing in the quota price, increasing enforcement reduces quota demand. Where the violation rate is unchanging in the quota price, increasing enforcement has no effect upon quota demand, which implies that here the non-compliant quota demand must equal the compliant quota demand. This represents a proof of the result found by Hatcher [8], which we can restate as 
Result A3. (Hatcher) With expected penalties for quota non-compliance dependent upon relative violations, the quota demand of a non-compliant firm exactly coincides with that of an otherwise identical compliant firm at the quota price at which the non-compliant firm's relative violation rate is at a maximum. At lower quota prices, the non-compliant quota demand is lower, but at higher quota prices the non-compliant quota demand is higher than that of an otherwise identical compliant firm. 


\section{References}

[1] L. G. Anderson, A note on market power in ITQ fisheries, J. Environ. Econom. Management 21 (1991) 291-296.

[2] L. G. Anderson, The control of market power in ITQ fisheries, Marine Res. Econom. 23 (2008) 25-35.

[3] C. W. Armstrong, Using history dependence to design a dynamic tradeable quota system under market imperfections, Environ. Res. Econom. 39 (2008) 447-457.

[4] C. Chavez, H. Salgado, Individual transferable quota markets under illegal fishing, Environ. Res. Econom. 31 (2005) 303-324.

[5] H. van Egteren, M. Weber, Marketable permits, market power and cheating, J. Environ. Econom. Management 30 (1996) 161-173.

[6] C. Hagem, H. Westskog, The design of a dynamic tradeable quota system under market imperfections, J. Environ. Econom. Management 36 (1998) 89-107.

[7] R. W. Hahn, Market power and transferable property rights, Q. J. Econom. 99 (1984) 753-765. 
[8] A. Hatcher, Non-compliance and the quota price in an ITQ fishery, J. Environ. Econom. Management 49 (2005) 427-436.

[9] A. Hatcher, Firm behaviour under pollution ratio standards with non-compliance, Environ. Res. Econom. 38 (2007) 89-98.

[10] R. Innes, C. Kling, J. Rubin, Emission permits under monopoly, Natur. Res. Modeling 5 (1991) 321-343.

[11] A. Malik, Markets for pollution control when firms are noncompliant, J. Environ. Econom. Management 18 (1990) 97-106.

[12] A. Malik, Further results on permit markets with market power and cheating, J. Environ. Econom. Management 44 (2002) 371-390.

[13] D. A. Malueg, Welfare consequences of emission credit trading programs, J. Environ. Econom. Management 18 (1990) 66-77.

[14] W. S. Misiolek, H. W. Elder, Exclusionary manipulation of markets for pollution rights, J. Environ. Econom. Management 16 (1989) 156-166.

[15] E. S. Sartzetakis, Tradeable emission permits regulations in the presence of imperfectly competitive product markets: welfare implications, Environ. Res. Econom. 9 (1997) 65-81. 
[16] E. S. Sartzetakis, On the efficiency of competitive markets for emission permits, Environ. Res. Econom. 27 (2004) 1-19. 